ARTIGOS 



\section{A fuga da escravidão imperial: Benedita Luiza os jogos de fronteira entre novos Estados (Bolívia e Brasil)}

Ernesto Cerveira de Sena*

Resumo: Em 1850, momento em que uma nova lei antitráfico entrava em vigor no Brasil, Benedita Luiza, uma escravizada, empreende fuga do Império, em Mato Grosso, até a Bolívia. Com esse episódio foram suscitados problemas típicos dos novos países modernos que surgiam, como os relacionados à soberania, e até onde iriam a territorialidade nacional, a legitimidade da propriedade em contraposição à fuga internacional. O texto mostra que, em meio a essas discussões, os representantes do Império aproveitaram tal momento para ocupar e praticamente sedimentar ocupações nas áreas fronteiriças. A Bolívia, por seu turno, em posição mais frágil na fronteira, mostrou-se receptiva aos fugitivos do Brasil, o que poderia trazer possibilidades de barganha em um acordo internacional sobre limites, que seria realizado mais cedo ou mais tarde. Palavras-chave: Bolívia. Brasil. Escravidão negra. Estados modernos. Fronteiras.

Este texto aborda a fuga de uma escrava chamada Benedita Luiza, de Mato Grosso para a república boliviana, e a apropriação de um espaço territorial, na época da construção das fronteiras internacionais dos novos países, que surgiam após a crise dos impérios ibéricos. Partimos do pressuposto conceitual de que a construção de limites nacionais era uma contingência dos Estados nacionais que se formavam no século XIX (FOUCHER, 1986). Ou

"Doutor em História Social e das Ideias pela Universidade de Brasília - UNB, com estágio pós-doutoral na Universidade Federal Fluminense - UFF. Professor de História da América na Universidade Federal de Mato Grosso - UFMT. A pesquisa conta com o apoio do CNPq. E-mail: ernesto.sena@gmail.com. 
seja, tinha-se a perspectiva contingencial de que, a partir da ruptura com a metrópole, as novas unidades políticas deveriam estabelecer oficialmente seus limites territoriais com os vizinhos, por tratado ou por decorrência de guerra. Tal contingência era a afirmação da nova ideia de soberania na América, que se deslocava do corpo do monarca, do outro lado do Atlântico, para recair no "povo", assentado no solo de sua própria "pátria”, que impulsionariam o surgimento de novos Estados nacionais (GUERRA, 2009; CHIARAMONTE, 2004). ${ }^{1}$ O território, então, notadamente no caso das Américas, com sua população heterogênea, assume uma forte conotação de lugar apropriado e reservado para o exercício da nova soberania nacional (PAMPLONA; DOYLE, 2009).

No caso específico da fuga de Benedita Luiza, foram realçados pontos sensíveis às novas soberanias no mundo moderno, pós-independências, na região de fronteira entre o Brasil e a Bolívia. A atitude individual de evasão de uma cativa trouxe à tona questões relativas às políticas internacionais, tais como a legitimidade de sua fuga (ou seja, em que medida atingiria, por aspectos legais ou morais, a questão da soberania), a possibilidade de asilo na república boliviana e, principalmente, quais seriam, ou deveriam ser, os limites das terras do Império e da Bolívia em meados do século XIX, quando os dois países ainda não haviam assinado nenhum acordo diplomático nem tido conflitos abertos em relação às suas fronteiras. A não devolução da negra, por parte da Bolívia, demonstrava a estratégia adotada pelas autoridades bolivianas naquele momento. Foi uma maneira de fazer frente às ocupações territoriais em andamento por brasileiros, tendo em vista seus poucos recursos para se defender na zona fronteiriça.

Benedita Luiza empreendeu fuga ao final de 1850, adentrando parte da zona fronteiriça em área geográfica então considerada boliviana tanto por representantes do Brasil como da Bolívia. Ela fugiu de sua "senhora" de um lugar chamado Tremedal, antes tido como parte das terras da república fundada por Sucre, mas recém-ocupado por tropas e colonos brasileiros (lugar atualmente situado no oeste de Mato Grosso), não muito distante de outros pueblos e ranchos do mesmo país. ${ }^{2}$ A evasão fez com que o presidente de província 
de Mato Grosso pedisse sua extradição imediata, alegando haver "direitos" de brasileiros sobre ela. Apontava-se que a cativa teria passado para o outro lado por ter sido "seduzida" por um boliviano. Tal evento, além de protestos oficiais de autoridades brasileiras, levantava outras indagações sobre a zona de fronteira entre os dois países. Estava em jogo o entendimento do limite territorial entre ambos, como assinalamos. À Bolívia, recaía o exercício de sua soberania em seu próprio solo. Ao Império, o destino da escrava seria relacionado principalmente à ilegitimidade de sua evasão e aos direitos de seus nacionais.

Esses pontos de discordância traziam consigo uma historicidade da própria zona fronteiriça, em diálogos ou em atitudes autônomas relacionados às respectivas capitais, Rio de Janeiro e La Plata (ou Chuquisaca, hoje em dia chamada de Sucre ${ }^{3}$ ), as quais ansiavam por maiores fluxos de materiais e ideias com o exterior. Não obstante, era nos lugares fronteiriços que apareciam situações, demandas e questões candentes. Era aí, na zona fronteiriça, que se projetavam com bastante força, explicitada ou de maneira implícita nas documentações, os posicionamentos das autoridades locais relacionados ao próprio exercício da nova soberania nacional. Tal campo de embate suscitava o problema do reconhecimento de ambos os vizinhos sobre seus respectivos solos pátrios, cuja concepção e materialização estavam em construção.

\section{Soberania com escravidão}

Em meados do século XIX, tornava-se cada vez mais distante (mas não nula) a ideia de recolonização dos países americanos por suas ex-metrópoles, com apoio especialmente de outros países europeus. Ao mesmo tempo, certa integração à Europa ou aos Estados Unidos mostrava-se extremamente necessária diante do padrão "civilizacional" e de "progresso", típico do século oitocentista, com traduções locais (QUIJADA, 2000). ${ }^{4} \mathrm{Ou}$ seja, em geral, os novos Estados sul-americanos não mostravam possibilidades efetivas de prescindir do grande comércio mundial, que crescia 
A fuga da escravidão imperial: Benedita Luiza os jogos de fronteira entre...

exponencialmente durante a maior parte do Oitocentos, como também não poderiam abrir mão do reconhecimento político de seus próprios países pelo exterior.

Nesse bojo, a Grã-Bretanha conseguia imprimir uma hegemonia no Ocidente, construída desde o início do XIX, insuflando a produção de matérias-primas ou semielaboradas na "periferia", para suprir as demandas crescentes de sua expansão industrial e de seu mercado consumidor, tanto doméstico quanto fora dele. Como mostra Tomich (2011), nessa rearticulação da economia mundial pós-independência nas Américas, com a queda dos antigos monopólios coloniais, novas (ou revitalização de antigas) zonas de produção agrícola, notadamente as de açúcar, algodão e café, receberam quantidades inéditas de escravizados trazidos da África, coadunando com a produção que aumentava exponencialmente desses itens de exportação. Juntava-se a isso a maior oferta de créditos para essas mesmas áreas de expansão agrícola, especialmente de origem britânica, mas que abriam espaços para prosperar rentistas também de outros centros financeiros, como os de Nova York, o que fomentava um mercado multilateral (TOMICH, 2011, p. 89). Dessa forma, como indica o autor, a escravidão não se mostrava incompatível com o desenvolvimento do comércio e das finanças globais. Pelo contrário, essa "Segunda Escravidão" era elemento chave tanto para os preços de mercadoria que passaram a ser cotadas em um mercado aberto, passando pelos investimentos em transportes, quanto para os próprios salários dos trabalhadores das áreas industriais. Enfim, o autor chama de "Segunda Escravidão" essa maior demanda e esse emprego de mão de obra africana em um novo cenário econômico e político, notadamente no pós-independência nas Américas. Ela conviveu lado a lado com as formas novas e mais eficientes de comunicação e produção, mostrando a "adaptabilidade e vitalidade" do regime durante boa parte do século XIX (TOMICH, 2011, p. 86-97).

Isso não impediu que fosse a Grã-Bretanha, desde as primeiras décadas do século XIX, de ser o principal país a levantar a bandeira do abolicionismo e do livre-comércio (mesmo tendo dissenções internas). Os líderes britânicos consideravam essencial não somente forçar a queda de preços dos produtos primários com maior oferta 
deles, em contrapartida ao que vinha acontecendo com os produtos industrializados ingleses, mas também atender a questões morais e aos novos entendimentos de uma economia política pró-trabalho assalariado, encetados por abolicionistas do hemisfério ocidental. Tais diretrizes acabaram sendo a política oficial inglesa.

Dessa maneira, a hegemonia inglesa no comércio e nos mares não significou a diminuição do grande tráfico negreiro. Deu-se o contrário. Na primeira metade do século oitocentista, a importação de escravos para as grandes áreas de escravocratas, como Brasil, Cuba e o sul dos Estados Unidos, atingiram suas maiores marcas, como mostra Tomich (2011, p. 81-83). Formava-se, então, uma grande tensão nas relações internacionais no Atlântico, resultante da pressão inglesa pelo fim do tráfico (acompanhada de um horizonte abolicionista), a forte expansão agrícola nas "periferias" e o incremento do comércio infame, seguido por sua relutância, especialmente nas décadas de 1830 a 1860.

Justamente analisando as políticas nacionais e internacionais das maiores regiões escravagistas e da Grã-Bretanha, Bivar Marquese e Parrom (2011) apresentam determinadas articulações entre o sul dos Estados Unidos, Brasil e Cuba. Desde o início do século, esses lugares conseguiam implementar uma política interna que assegurava a manutenção da escravidão. De certa maneira, coadunando os planos internacionais e nacionais, acabaram se mostrando interdependentes ao se postarem como antagônicos à pressão inglesa, que, no correr do Oitocentos, só tendia a aumentar. Se tal "articulação" não se apresentava como política explícita, ela se apresentava como referências mútuas sobre a viabilidade do trabalho escravo, em meio à crescente opinião pública sobre sua inequidade. $\mathrm{O}$ fim de uma dessas áreas escravagistas seria prejudicial à outra. Assim, os homens públicos defensores da escravidão negra demonstravam que resistir à Grã-Bretanha seria questão de "soberania", e vital para o "progresso" de seus respectivos lugares (MARQUESE; PARROM, 2011, p. 107).

Nesse contexto, o Brasil parecia se diferenciar cada vez mais das repúblicas vizinhas sul-americanas ao explicitar seu apego ao trabalho cativo negro. Villafañe Gomes Santos (2003) mostra que, no início dos novos países, o Império trazia a imagem de um "estranho 
A fuga da escravidão imperial: Benedita Luiza os jogos de fronteira entre...

no ninho" em meio a tantas repúblicas recém-formadas. Vizinho de quase todos os países da América do Sul, além de manter e defender abertamente a escravidão, poderia inclusive sofrer a acusação de ser o representante das antigas monarquias europeias na América, e, então, colaborar para a implementação de uma "recolonização" pelas antigas dinastias europeias.

Dessa maneira, na primeira metade do século XIX, a política exterior do Brasil foi de precaução em relação aos demais países do subcontinente sul-americano. Isso se dava porque o Império receava uma união entre os vizinhos republicanos para tratarem de assuntos espinhosos como os limites territoriais e a escravidão. Para forjar tal unidade, os vizinhos - além de serem repúblicas - poderiam utilizar o argumento antiescravagista, o que acabaria por deixar o Império em situação defensiva. Essa união, no entanto, nunca se efetuou, embora ao longo do século XIX, tenham se realizado vários congressos de chefes de Estado, os quais não tiveram a participação do Império do Brasil (GOMES SANTOS, 2003, p. 21-31). Ao contrário, os países e as regiões da Bacia Platina tinham como pautas mais importantes a livre navegação nos rios da Bacia e os limites territoriais internacionais (FERREIRA, 2009), e era onde investiam mais suas energias e não, como mostra Blanchard (2008), qualquer defesa imaginária de uma alforria negra para todo o continente.

Em relação à Bolívia, especificamente, o Brasil também desenvolveu certa política imperial, mas não tão intensa como no restante da região platina. Mesmo sem nenhum dos dois países destacarem, em meados do século XIX, as suas relações frente aos demais vizinhos, as ações do Império foram suficientes para a obtenção de terras junto à república com maior extensão territorial, como veremos.

A Bolívia, em suas primeiras décadas, imprimia mais esforços nas zonas de fronteira com o Chile e o Peru, onde via maior necessidade de defesa ou afirmação de sua nova soberania. A República, de fato, era muito mais voltada para o Pacífico. A maioria da população encontrava-se na região andina, enquanto o oriente boliviano era considerado "vazio" ou pouco povoado. ${ }^{5}$ De todo modo, mesmo que as Tierras Bajas ${ }^{6}$ não atraíssem as principais atenções da república boliviana, ela, como muitos dos novos países que surgiam na América do Sul, sabia que em algum momento teria 
de assinar acordos sobre seus limites territoriais com os vizinhos. A esses acordos, normalmente, seguiam-se diversas regulamentações - entre outras, sobre comércio, de "amizade" (não hostilidade e possível cooperação), além de extradição de trânsfugas.

\section{Escravizados em fronteira: estratégias e imagens para o exterior}

$\mathrm{Na}$ América do Sul, os embates a respeito da mão de obra cativa não estavam dissociados das disputas por limites territoriais. Enquanto a Grã-Bretanha concorria para que os países do Atlântico adotassem o princípio do "solo livre da escravidão", como uma das formas de combater o tráfico (MARQUESE; PARROM, 2011, p. 98-99), o Império do Brasil, na década de 1850, emplacou nas suas relações com países da região amazônica, do Peru e da Colômbia, tratados de extradição de escravizados fugitivos (GOMES SANTOS, 2003). Na região platina, os membros do Partido Colorado, no Uruguai, também assinaram acordos com o Império para a devolução de cativos. Por outro lado, Buenos Aires, sob Rosas (1835-1852), assim como os blancos, ocupando ou pressionando Montevidéu (1825-1828, 1830-1834, 1839-1851), agiriam de maneira oposta, com acenos de liberdade para os escravizados que fugissem de seus senhores brasileiros. ${ }^{7} \mathrm{Ou}$ seja, os escravizados eram parte do jogo que envolvia os limites territoriais e a proteção dos rios, duas questões fundamentais para a soberania dos novos Estados nacionais.

As guerras de independência na América hispânica abriram possibilidades significativas para a conquista da "liberdade" por parte de numerosos escravizados. Atraídos por possível alforria, foram integrados tanto nos grupos de "realistas" como nos "patrióticos", ou simplesmente eram "emprestados" por seus senhores. Se para os criollos a luta contra a "opressão" do rei tornou-se a luta pela liberdade do seu país, ${ }^{8}$ para muitos negros escravizados, o estado belicoso poderia ser a luta ou a oportunidade para a própria mudança de status (BLANCHARD, 2008, p. 115 e ss). Ao mesmo tempo, os escravizados, eles próprios, também representavam uma 
A fuga da escravidão imperial: Benedita Luiza os jogos de fronteira entre...

força a ser temida, vindo sempre à memória de líderes o exemplo de Saint Domingue como o terror máximo, em meio à necessidade de mantê-los sob controle. ${ }^{9}$

Tal utilização política dos cativos, aliando o temor da haitianização com a alforria, também se fez presente na capitania fronteiriça de Mato Grosso com a futura Bolívia, nos anos iniciais da década de 1820, no momento de ruptura com a metrópole. No processo de independência brasileiro, despontou a rivalidade entre Vila Bela e Cuiabá para decidirem qual das duas seria a capital na nova configuração política. Assim, a junta governativa vila-belense chegou a prometer a liberdade aos escravizados como estratégia de conflito regional (SIQUEIRA, 2002), procurando enfraquecer as elites da baixada cuiabana. Tal medida acabou afastando o apoio de outras localidades para a junta, antes tido como certo, como foi o caso de Vila Maria. No geral, os principais grupos políticos e senhores proprietários ficaram temerosos com o resultado de tal medida. Essa proposta, depois de bastante estardalhaço, acabou não vingando, inclusive na própria Vila Bela, sendo veementemente desqualificada e seu proponente, isolado do jogo partidário (LIMA, 2012).${ }^{10}$ Assim, a instituição escravista já dava sinais de que mais poderia provocar a união de elites locais do que separá-las e enfraquecê-las.

Com o fim das guerras de independência na América hispânica, muitos dos escravizados se viram frustrados quanto ao desejo de alforria imediata. Como enfatiza Blanchard (2008, p. 160), as lutas pela independência não se deram pela liberdade dos escravizados, mas sim contra a Espanha, por mais que os cativos dela participassem. O medo da haitianização não desapareceu nas décadas seguintes. Temia-se que ressurgisse uma guerra baseada em fundamentos raciais. Ao mesmo tempo, quando se começou a tratar do soerguimento econômico da América, notadamente na andina, da qual a Bolívia era parte, as ideias liberais (de cidadania e de liberdades frente ao mundo de "castas") não puderam fazer frente aos donos de terras e de áreas de mineração, que continuaram a possuir escravizados negros e a submeter grupos indígenas à pongueaje, em meio a uma legislação que ainda sustentava o imposto indígena, visto como um "fóssil" do tempo colonial. ${ }^{11}$ 
Não foram poucos na América hispânica que também argumentavam que a "propriedade" de escravizados, por "direito", não era incompatível com a época de "progresso" e "civilização". Pelo contrário. Os escravizados foram vistos como essenciais para a reconstrução das terras depois das guerras e para a competição econômica diante de mais produtores de matérias-primas (LOMBARDI, 2003). Dessa maneira, foi extremamente comum imprimir nas legislações nacionais a protelação da "liberdade" dos escravizados em toda a América hispânica. Na Venezuela, por exemplo, Lombardi (2003, p. 380-381) mostra que a proclamação de Bolívar estabelecendo o fim da escravidão, em 1814, atendia principalmente a seu grupo guerreiro (em oposição aos grandes plantadores), interessado muito mais em compensar suas várias derrotas nos campos de batalha. $\mathrm{O}$ fim legal da escravidão somente foi efetivado em 1854, ou seja, 36 anos depois da famosa declaração. ${ }^{12}$

Em geral, as leis do ventre livre passaram a ser um estágio antes da alforria definitiva na América ibérica. Normalmente, estabeleciase a obrigatoriedade do trabalho do filho de escrava até os dezoito ou 21 anos, como forma de compensar os "prejuízos" do dono da genitora. Era, sem dúvida, uma maneira de tentar assegurar por mais algum tempo mão de obra supostamente "dócil”. Isso, contudo, não evitou que negros escravizados ou livres promovessem guerrilhas logo após as independências, como insatisfação ante os rumos dos novos países, ou manifestações de sua própria independência frente às diretrizes que tomaram os novos países em que habitavam e lutaram pela independência (LOMBARDI, 2003, p. 379-381).

Sobre a Bolívia, especificamente, tem grande valor o trabalho pioneiro de Crespo (1977), baseado nas constituições republicanas, principalmente se considerarmos que até a atualidade são muito poucos os trabalhos que tratam da escravidão de negros na república boliviana. ${ }^{13}$ Se a Constituição de 1826 concedia uma "liberdade" inicial para todos os escravizados negros (presumia-se que o indígena não era e não poderia ser "cativo" desde o período colonial, embora, de fato, persistisse o trabalho coercitivo e agenciado), ainda que condicionada a uma "indenização" ao "amo", logo apareceriam outras legislações prorrogando a manutenção da escravidão negra. Em 1830, um dispositivo jurídico estabelecia que somente 
A fuga da escravidão imperial: Benedita Luiza os jogos de fronteira entre...

poderiam ser livres aqueles que tivessem nascido a partir de seis de agosto de 1825, justamente a data comemorativa do aniversário da independência boliviana (CRESPO, 1977, p. 92).

A Constituição de 1851 restabeleceu o princípio de que "[...] todo hombre nasce libre en Bolivia; todo hombre recupera su libertad al pisar su território. La esclavitud no existe ni puede existir en él [...]", tal como apareceu na primeira Carta Magna. Depois, tal premissa é repetida em 1868, em outra Constituição (CRESPO, 1977, p. 193). Provavelmente essa repetição tenha ocorrido justamente porque a escravidão de negros permanecia a olhos vistos, apesar das disposições legais em contrário, como mostram Cerveira de Sena (2013) e Revilla Orías (2014).

A ideia de "solo livre", como afirma Grinberg (2007), fortaleceu-se "ao longo do século XIX", no momento em que as fronteiras nacionais começavam a ser definidas. Colocava-se para o debate se a escravidão seria "legítima" ou "ilegítima” em dado país, o que influía sem dúvida nas relações internacionais. Assim, considerar "a permanência da escravidão" em pleno Oitocentos, quando vários países a rejeitavam, implicava aceitar que o regime de trabalho de escravizados em larga escala estava sobretudo circunscrito a um dado território.

De acordo com Secreto (2015), antes das independências, a ideia de "solo livre" já era usada em determinadas ocasiões, recorrendo a tradições da península ibérica, mas na América implicava principalmente não devolver escravizados fugidos e tentar atrair cativos dos rivais para desestabilizá-los. Também se alegava os "tratamentos inadequados" que o escravizado sofreria nas áreas de cativeiro. No mundo ibérico, tal como na época da "reconquista" da península, isso fazia parte das tentativas de incorporar mais terras, ao mesmo tempo que diminuía as explosões de descontentamento em territórios conquistados. Em geral, com rupturas e continuidades, os códigos antigos relacionados à lida com escravizados se faziam presentes. Então, o direito de asilo somava-se às várias estratégias das relações internacionais entre os impérios, seja em guerra, seja em negociações com outros países colonizadores.

No século XIX, após as independências, o princípio do "solo livre” foi preconizado pela Bolívia já na sua primeira Constituição, 
de 1826, aliando, como já assinalamos anteriormente, à "liberdade" de cativos. Ou seja, além do pressuposto da liberdade de quem estivesse no território republicano, também quem nele entrasse não poderia ser reduzido à condição de escravo. Isso não chegou a impedir que houvesse escravizados negros claramente sendo vendidos e comprados, pelo menos durante a década de 1830 e 1840, como apontou Revilla Orías (2014, p. 233), e que na fronteira de Mato Grosso fossem devolvidos aos donos brasileiros, como mostrou Sena (2013, p. 92-94).

Mesmo assim, como em muitos países na América ibérica pós-abolição, era necessário assinalar para outros países europeus, principalmente à Grã-Bretanha, que não existiria mais escravidão ou que ela estaria em vias de extinção. A necessidade de reconhecimento dos novos países por outras "nações" que expressavam potência militar e comercial no Ocidente, certamente, facilitaria o ansiado intercâmbio de mercadorias e representações diplomáticas, além de poder neutralizar hostilidades de outras potências ou mesmo de países vizinhos.

Dessa maneira, se na Bolívia ainda se via a presença de escravizados negros no interior de seu território, sua política externa procurava demonstrar imagem contrária à escravidão negra (SENA, 2013; REVILLA ORÍAS, 2014), como maneira de se relacionar melhor com as grandes potências, notadamente a Inglaterra. No Ocidente, em geral, estava cada vez mais difícil sustentar o regime de trabalho cativo como regime instituído. Economicamente, conforme apontou Revilla Orías (2014, p. 233), não era mais percebido como vantajoso para a República insistir no regime escravista; mas isso era exatamente o contrário, como já assinalamos, de como era percebido por elites políticas do Brasil, de Cuba e do sul dos Estados Unidos. De toda forma, a tensão no Atlântico derivada da migração forçada de africanos e a proeminência inglesa corroboraram a implementação da lei do fim do tráfico negreiro, em 25 de setembro de 1840, assinada pela Bolívia ao lado da Grã-Bretanha, já "tradicional" concessora de créditos para a "periferia" e, nesse momento, a principal tratadora do comércio global. Isso era uma considerável tentativa de a república impulsionar suas atividades, 
A fuga da escravidão imperial: Benedita Luiza os jogos de fronteira entre...

notadamente as mineradoras, que se encontravam praticamente destruídas desde as guerras de independência (BETHELL, 2002).

Em meados do século XIX, a Bolívia possuía uma população de escravizados negros considerada pequena tanto em face aos demais países da América do Sul quanto ao total de sua população. Em levantamentos censitários durante os anos 1840, publicados no ano de 1851, foram contabilizadas menos de 1.400 pessoas negras escravizadas, ante uma população de 1.373 .896 habitantes, com a maioria classificada como indígenas e mestizos (DALENCE, 1851). Mesmo podendo-se desconfiar desses números, como de qualquer censo do século XIX, Lisocka-Jaegermann (2011) mostra que a grande "dicotomia" produzida na Bolívia, na sua busca por civilização, era blancos versus índios (resultando daí um lugar de síntese para o mestizo, para o bem ou para o mal), o que deixava para o descendente de africano menos que uma área bem periférica nos discursos e nas políticas nacionais, quando não o seu completo apagamento. ${ }^{14}$

Assim, mesmo sendo pouco expressivo o número de escravizados negros, os governantes bolivianos, de maneira aparentemente contraditória, ao afirmarem para o exterior que a Bolívia seria "solo livre da escravidão", apontavam justamente para o calcanhar de Aquiles de seu vizinho, o Império do Brasil, onde a escravidão negra era um dos pilares de sustentação do regime monárquico e o que dificultava suas relações com os países lindeiros. A escravização, portanto, era o que colocava o Brasil no mundo atlântico, pós-independência, em situação no mínimo desafiadora, tendo em vista a necessidade de estabelecer, como qualquer novo país, suas relações internacionais e os seus limites territoriais.

\section{A fuga da escrava Luiza e as relações do Império com a Bolívia}

Se quando a Bolívia se formou a quantidade de negros não chegava a dar a cor de sua mão de obra, em Mato Grosso, a presença de escravizados negros, e demais descendentes de africanos, mostrava-se exatamente o oposto, o que frequentemente trazia temor 
aos proprietários de escravizados e de terras. Já no final das guerras de independência, espalhou-se um boato de que Bolívar - que não fazia jus à fama de "libertador" - ultrapassaria as fronteiras para libertar os escravizados da província vizinha. A falsa notícia foi suficiente para deixar os governantes e senhores de escravizados bastante intranquilos, temerosos de uma sublevação negra, pois parte das tropas independentistas, de fato, estava perto de Santa Cruz de la Sierra (SECKINGER, 1985). A entrada no Império não aconteceu, mas o boato evidenciou o receio brasileiro em relação aos cativos num momento de grande instabilidade política.

$\mathrm{Na}$ verdade, como mostra Luiza Volpato (1993), o medo de rebeliões escravas era constante, tanto na cidade como no campo, e o pavor aos quilombos somente diminuiu na década de 1870. Devido a esse medo, houve uma série de códigos e a observância de sua aplicação, na tentativa de disciplinar não somente os escravizados, mas os pobres em geral. No entanto, no cotidiano da capital da província, era difícil distinguir as pessoas pobres dos cativos, pois todos faziam muitas atividades lado a lado, do trabalho ao lazer (VOLPATO, 1996).

Por outro lado, desde o período colonial, já havia uma larga experiência de fuga de escravizados de Mato Grosso para o lado “espanhol”, que continuou após as independências. Houve casos de escravizados que, retirados do interior da África e após desembarcar no Rio de Janeiro, seguiram por meses de viagem até a fronteira oeste do Império. Por meio da fuga, estenderam suas odisseias até o império espanhol, como verdadeiros "homens de ferro", e "mulheres de pedra”, sendo depois localizados em tribunais de jurisdição na costa do Pacífico (RODRIGUES, 2015).

Os governos locais e senhores mato-grossenses tomavam várias medidas contra essas evasões, como descobrir rotas e montar guarda nas matas. Já na época dos Estados nacionais, eram enviadas expedições de guardas brasileiros, que adentravam o território boliviano levando recompensas para "resgatar" os fugidos, além de armas para eventuais problemas. Certa negociação entre autoridades locais permitia isso naquele momento ${ }^{15}$. Também foram estabelecidos postos na zona fronteiriça para o pagamento de recompensas ao boliviano que encontrasse um fugitivo, o que claramente aconteceu 
A fuga da escravidão imperial: Benedita Luiza os jogos de fronteira entre...

até parte da década de 1840. Quando a Bolívia cessou tal transação, houve protestos contundentes e mesmo ameaças por parte das autoridades mato-grossenses às de Santa Cruz de la Sierra, o mais extenso departamento boliviano que fazia divisa com a província de Mato Grosso ${ }^{16}$.

Quando a escravizada Benedita Luiza - descrita nos ofícios bolivianos ora como "morena", ora como "negra" - partiu do lugar recém-ocupado por tropas brasileiras, chamado Tremedal, acabou se inserindo nos jogos de fronteira, mesmo que sua atitude possa ser lida como individual". O vilarejo de Tremedal, ou "El Tremedal", tinha sido ocupado por tropas brasileiras (e por colonos) em 1848, ou seja, pouco antes da chamada "política ativa" do governo imperial (GOMES SANTOS, 2002, p. 65 e ss.), expressa especialmente por sua atitude mais incisiva no Prata. Segundo uma autoridade boliviana, um dos culpados dessa ocupação foi o então administrador boliviano do lugar, que teria cooperado com a invasão e ainda teria queimado a cruz de madeira que ficava em lugar visível ao público (a cruz simbolizava o departamento de Santa Cruz, e sua queima não era necessariamente um ataque à Igreja Católica), entre outros "hechos nada decorosos"18. A reação das demais autoridades bolivianas foi tentar reunir soldados e reclamar para o representante brasileiro que estava em Chuquisaca (atual Sucre) tentando negociações com a Bolívia sobre limites e extradições. Caso não houvesse um acordo entre autoridades nacionais ou locais, era de se esperar que tal invasão pudesse colocar por terra o "bom entendimento" que oficialmente os dois países diziam ter ${ }^{19}$. Nos cálculos das autoridades da Bolívia, ainda pior do que a ocupação de Tremedal era a ameaça de que estaria próxima a tomada das "Salinas", onde estaria instalado o "Marco do Jauru", e também onde o "defensor de la frontera", D. Sebastián Ramos, tinha montado estância ${ }^{20}$.

Desde 1844 já havia reclamações do intitulado "defensor de la frontera" sobre rondas de soldados saídos de Mato Grosso, o que trazia transtornos à população local do vale do rio Jauru. Sabia-se que por essa via fluvial poderia se chegar com embarcações até o rio Paraguai e daí, passando por outros dois grandes rios platinos, ao Atlântico. A rota ainda era vista pela Bolívia como uma possibilidade, mesmo que os portos do Pacífico continuassem a se apresentar 
como caminho mais importante e viável, de onde, contornando o Cabo Horn ou seguindo para os portos da América Central ou do Norte, se poderia seguir rota até o Atlântico e, assim, garantir a inserção boliviana nos principais mercados mundiais (KLEIN, 2008).

No entanto, o Império do Brasil procurou controlar as duas margens do rio Jauru, para desgosto do próprio Sebastián Ramos, que se utilizava dessa via para seus negócios na região. $\mathrm{O}$ rio também era uma referência para o que seria a borda do território boliviano, caso o que tinha sido o Tratado de Santo Ildefonso, de 1777, fosse adotado pelos dois países ${ }^{21}$. Em situações como essa, as autoridades bolivianas de fronteira, e por vezes o governo central da Bolívia, praticamente só poderiam expedir notas oficiais de protesto, sem que surtissem os efeitos esperados para recuperar o espaço perdido. Tudo demonstrava que a chance de reapropriação dessas terras somente aconteceria quando um tratado oficial entre os dois países fosse finalmente assinado, tendo em vista o pequeno número de soldados da República na região, a precariedade da ocupação civil na fronteira, além das prioridades internacionais bolivianas se concentrarem na região andina. Muito provavelmente, um tratado seria a via desejada para que não se entrasse em conflito aberto contra uma potência regional, como acontecia com outros países ao sul, notadamente se fosse considerada a instabilidade interna que por vezes derrubava o presidente da República ${ }^{22}$.

De toda forma, com a fuga de Benedita Luiza, avolumou-se o número de reclamações das autoridades bolivianas em relação às atitudes dos brasileiros na zona fronteiriça. As tropas imperiais estavam se movimentando ostensivamente na região, o que fez com que os bolivianos receassem que o Império estivesse efetivamente se preparando para uma guerra contra a República ${ }^{23}$.

Em resposta a um dos ofícios, o presidente da província de Mato Grosso, Carlos Augusto Leverger, respondeu colocando-se de maneira aparentemente ambígua: de um lado, procurava acalmar os ânimos afastando qualquer possibilidade de organização para um conflito armado, reafirmando a paz e o "bom entendimento" entre os dois países ${ }^{24}$; de outro, procurava sedimentar a recente ocupação da colônia de Tremedal. Assim, informava que o cônsul do Brasil estava a caminho das repúblicas do Pacífico, incluindo 
A fuga da escravidão imperial: Benedita Luiza os jogos de fronteira entre...

a Bolívia, para tratar dos “ajustes de limites” entre os dois países. Esquivando-se, dizia que a questão da ocupação do Tremedal somente poderia ser tratada por autoridades diplomáticas, não mais entre autoridades locais. Em relação às correrias de brasileiros em outras partes do território boliviano, justificava-as principalmente pela fuga da escrava Benedita Luiza ${ }^{25}$.

Apesar das palavras de Leverger, as autoridades bolivianas prosseguiram pedindo socorro para suas fronteiras, e tropas brasileiras continuaram a entrar no território da República. Tais correrias eram amiúde justificadas pela tentativa de captura de outros escravizados e desertores fugidos do Brasil $^{26}$. Em relação à vulnerabilidade dos povoados e das terras, uma autoridade local boliviana, o juiz territorial das Salinas, demonstrava, dessa maneira, a situação da região ao administrador do povoado de Santo Corazón: "[...] ninguna respetabilidad [...] hay en nuestra frontera porque los pocos naturales chiquitanos que tengo la mayor parte son ancianos y aun estos se hallan al presente todos gravemente enfermos de la peste". Assim, para a defesa, contaria somente com três vecinos dispersos, e para contatá-los e articulá-los seria necessário ao menos uma "cavalgadura", mas nem disso dispunha naquele ponto avançado do território boliviano ${ }^{27}$.

Essa falta de "respeitabilidade" foi demonstrada notadamente logo após a fuga da escrava Benedita Luiza, quando sua própria senhora e seu sobrinho foram até a casa do juiz territorial, em San Matías, exigir sua devolução. Segundo o juiz, os dois brasileiros bateram na porta de sua residência requerendo a entrega da fugitiva. Ele negou que estivesse com ela e mandou os brasileiros saírem, ao que eles obedeceram. No entanto, era notória a fragilidade de defesa da fronteira, inclusive de seus povoados. Mesmo assim, a ideia dos bolivianos era não proporcionar o "resgate" da fugitiva, apesar das hostilidades.

As autoridades do Brasil procuraram representar, em suas cartas, que a fuga e a sua não extradição eram ilícitas. A escravizada teria sido "seduzida" por um comerciante boliviano chamado Barba. Por parte da Bolívia, desde administradores de "cantões" (como se chamava à época o que seria mais ou menos os municípios do Brasil), do governador de Chiquitos ${ }^{28}$ (então governadoria 
que englobava vários cantões) até o prefeito do departamento de Santa Cruz (o prefeito era o cargo que corresponderia, mais ou menos, ao de presidente de província no Império), todos defenderam que não havia ocorrido "sedução" - ou seja, que ela teria sido convencida a deixar "sua" senhora ${ }^{29}$. Ao contrário, ela teria fugido devido aos "maus-tratos" que recebia de sua dona. Em relação ao negociante Barba, defendiam que ele, como outros bolivianos, nem sequer conseguia passar do "primeiro posto" da guarda brasileira ${ }^{30}$ - enquanto a pretensa senhora de Luiza e seu sobrinho haviam entrado livremente na Bolívia procurando resgatá-la.

Ao focar na acusação de "sedução" de Benedita Luiza, o presidente de província procurava desqualificar a atitude da escravizada ${ }^{31}$, não só retirando sua vontade própria, mas também, acreditamos, forjando uma maneira de abrir possibilidades para futura deportação. $\mathrm{Na}$ verdade, o Império do Brasil não tinha nenhum tratado em vigor com a Bolívia, embora já tivessem ocorrido conversas diplomáticas para que houvesse algum acordo oficial. Caso surgisse um termo oficial, como aconteceu com outros países, o fato de a fugitiva ter sido "seduzida" poderia ser uma das vias para qualificá-la como extraditável, como veremos a seguir em condições semelhantes.

$\mathrm{Na}$ fronteira do sul do Brasil com o Uruguai, estudos mostram como estancieiros conseguiam reaver seus cativos devido a acordos diplomáticos. Por outro lado, foi também por tratados entre esses dois países e por meios judiciais internos ao Império que escravizados conseguiram a liberdade de seu senhor por terem adentrado território uruguaio e voltado ao solo sulista. Isso era invocado de acordo com a lei de 1831, que, além de abolir o tráfico transatlântico de africanos, também trazia esse dispositivo para os cativos que tivessem pisado em "solo livre". No entanto, essa possibilidade judicial somente passou a ser empregada na fronteira sul, principalmente a partir da década de 1860, quando a instituição escravista sofria fortes golpes também dentro do Brasil (GRINBERG, 2007).

No caso de Benedita Luiza, é importante assinalar que a fuga em si não era considerada crime, como mostra Flores (2014) ao analisar os delitos no sul do Brasil. A evasão de um escravizado poderia ser considerada crime se fosse qualificada como "sedução", ou seja, se terceiros tivessem convencido o cativo a fugir. Assim, 
A fuga da escravidão imperial: Benedita Luiza os jogos de fronteira entre...

a "sedução" assemelhar-se-ia a roubo ou furto, e o senhor, então, procuraria reaver sua propriedade ${ }^{32}$. Mas isso, lembramos, quando o acordo diplomático permitia, em meio às oscilações e instabilidades do Prata.

De toda forma, o presidente de Mato Grosso, Leverger, na tentativa de reforçar que não entraria em guerra com a Bolívia, tinha proibido a "ronda" de soldados em locais da fronteira, como San Matías, nas proximidades do pueblo de Santo Corazón e na área a oeste do Jauru. Se sobre o Tremedal o assunto era somente para esferas maiores de agentes de Estado, dois anos depois, uma autoridade boliviana considerou que havia cerca de trezentos soldados brasileiros no lugar de onde Benedita Luiza havia fugido ${ }^{33}$. Esse cálculo, sobretudo, assinalava o quanto era difícil pensarem em uma retomada de posse. As possibilidades bolivianas na fronteira contrastavam com a ostentação do poderio bélico dos brasileiros, que faziam expedições ao território boliviano e conquistavam pontos cada vez mais a oeste.

Não sabemos muito sobre o destino da escravizada fugitiva, além de que foi mandada, por autoridade boliviana, internalizar-se no território republicano. Em certa medida, podemos dizer que essa falta de dados e de hipóteses tem a ver com os pouquíssimos trabalhos sobre a presença negra na República da Bolívia, o que se relaciona com a própria escassez de documentação sobre suas atividades em sociedade no XIX. Em geral, a historiografia boliviana trata da "questão" de indígenas e mestiços como mão de obra básica e suas formas de inserção na economia e política no período de formação das sociedades bolivianas ${ }^{34}$. De toda forma, sabe-se que o número de pessoas apontadas como descendentes de negros continua consideravelmente baixo e, como já nos referimos, era concentrada, durante o século XIX, no vale dos Yungas, perto da capital La Paz. Daí, aponta-se que teriam migrado para Santa Cruz de la Sierra, o que tornou essa cidade o segundo lugar com maior concentração de negros (LISOCKA-JAEGERMANN, 2011, p. 324). No entanto, podemos considerar que era para essa região fronteiriça que muitos escravizados fugiram desde o período colonial, inclusive formando quilombos (LORDELO, 2012). Nas primeiras décadas do período imperial, as fugas continuaram, para 
desespero dos "proprietários". Então, não seria de todo descabido imaginar que Benedita Luiza, no novo lugar em que foi viver e trabalhar, pudesse ter se encontrado com negros que também se libertaram de seus "donos" brasileiros, por mais que a Bolívia não fosse propriamente um "solo livre" da escravidão.

De toda forma, seja qual tenha sido o paradeiro e a inserção de Luiza no território boliviano, as práticas das autoridades da República passaram a demonstrar claramente que o "solo nacional" estava aberto às fugas de escravizados, além de desertores, que deixassem o território da monarquia sul-americana ${ }^{35}$. Era uma maneira de fazer frente ao vizinho mais numeroso e armado, ao menos enquanto o esperado tratado não fosse assinado. Assim, a atitude boliviana também se coadunava com a tendência ocidental, capitaneada pela Grã-Bretanha, que, por mais que houvesse oponentes resistentes e persistentes, previa em seus cálculos o fim do tráfico de escravizados retirados da África e a consequente extinção do cativeiro negro no Novo Mundo. Ao mesmo tempo, a Bolívia não deixava de esperar participar mais efetivamente do grande comércio mundial, para o qual dependeria bastante de suas relações com outros países. Além do Brasil, que poderia franquear navegação pelo Amazonas e quiçá pelo Prata (caso se tornasse hegemônico ou estabelecesse uma paz com equilíbrio de forças na difícil situação da região), havia Chile e Peru, com quem se relacionava visando à garantia da saída pelo Pacífico. Não menos importante seria sua relação com a Inglaterra, pois se configurava como a maior importadora mundial de commodities naquele momento, além de possuir a sede da City, o maior mercado financeiro do mundo ${ }^{36}$.

\section{Considerações finais}

O caso de Benedita Luiza deixa que percebamos a tomada de um espaço geográfico. A fuga da então cativa serviu como pretexto aos representantes do Império para sedimentarem ocupações da zona fronteiriça, em lugares que antes eram considerados bolivianos. Tremedal, ex-colônia boliviana de onde Benedita fugiu, não retornaria mais para a Bolívia. A região de Jauru, lugar que sofria várias 
A fuga da escravidão imperial: Benedita Luiza os jogos de fronteira entre...

"correrias" de soldados brasileiros, tendo já sido ocupado nas duas margens do rio de mesmo nome, acabou também ratificado como brasileiro devido ao primeiro tratado entre os dois países, assinado em 1867. Assim também foi com outras partes a oeste do rio Paraguai.

A fuga de Benedita Luiza também permite notar a ligação dessa região fronteiriça com a dimensão da conjuntura atlântica, da qual a lei de 1831, que previa abolir o tráfico e a consideração de "solos livres" no exterior, era parte, mas que cada vez mais forçava os países a tomarem posições frente ao comércio infame. Assim, os bolivianos, mesmo tendo escravizado negros em seu território, procuraram usufruir vantagem ao receber escravizados e outros fugidos em seu solo, pelo menos enquanto não houvesse algum acordo oficial. Adotava essa posição na medida de suas possibilidades, que eram muito mais precárias que as do Império, em especial nessa região fronteiriça. Seguramente, o efeito não foi promissor, a República não conseguiu fazer frente ao Brasil, mas não deixou de ser uma tentativa desafiadora à cobertura dada à escravizada Luiza.

Se a escravidão era o calcanhar de Aquiles do Império quando se tratava de negociações internacionais, a demonstração de poderio armado na região fronteiriça compensou, diante do vizinho, na busca de melhores condições para efetivar sua expansão territorial. Ao que tudo indica, a Bolívia temia - ou não lhe interessava - um conflito armado na região e acabou sendo o único país da América platina com o qual o Império não entrou em conflito aberto. Em troca, o Império não deixou de ferir a reivindicação de soberania territorial da Bolívia. Assim, a busca de liberdade da escravizada Benedita Luiza, indo para a Bolívia, acabou vinculando-se também à posse e ao respectivo controle de mais terras pelo Império do Brasil, ao estabelecer, na prática, limites geográficos ao vizinho naquele momento.

Como já assinalaram Bivar Marquese e Parrom (2011, p. 99), a política internacional pode ser melhor entendida se for vinculada à nacional, notadamente no caso da escravidão no século XIX. No caso da análise de região de fronteira, também podemos acrescentar atitudes locais relacionadas às políticas nacionais e internacionais. Localmente, na fronteira, respondia-se com graus variáveis às respectivas diretrizes capitais, ao mesmo tempo que essa mesma 
área também estabelecia demandas tanto para os centros políticos quanto para os representantes do país no exterior. Afinal, coube aos proprietários de Mato Grosso planejarem e executarem formas de evitar a evasão de escravizados, ou mesmo de "resgatá-los", enquanto governantes locais faziam as vezes de diplomatas ao se relacionarem com autoridades de escalões diferentes da Bolívia. Da mesma maneira, eram os moradores bolivianos da fronteira que procuraram resistir aos avanços brasileiros, enquanto tinham pouquíssimos recursos para assegurarem as terras nacionais e a política de recepção de fugitivos do Império. Assim, uma ligação mais efetiva da Bolívia com a Grã-Bretanha, ao abolir o tráfico, procurando mostrar ser "solo livre da escravidão", de nada adiantou para obter mais recursos para defender-se da expansão imperial, o que significava também a prática da escravidão. Justamente dessa forma foi o ponto geográfico de Tremedal, lugar recém-ocupado, mas que rapidamente já tinha senhores com escravizados, no caso, Benedita Luiza. Se o império, na década 1840, reclamava dos atentados à sua soberania quando ingleses aprisionavam navios negreiros na costa brasileira, o Brasil, por outro lado, em poucos anos, alargou-se para o oeste, sem deflagrar guerra, mas em detrimento das reivindicações bolivianas, promovendo o "solo cativo" no subcontinente sul-americano.

THE ESCAPE FROM IMPERIAL SLAVERY: BENEDITA LUIZA AND THE BORDER GAMES BETWEEN NEW NATIONAL STATES (BOLIVIA AND BRAZIL)

Abstract: In 1850, when a new anti-trafficking law went into effect in Brazil, Benedicta Luiza, a enslaved woman, escapes from the Brazil Empire, in Mato Grosso, to Bolivia. With this episode were raised problems typical of new modern countries that emerged, such as those related to sovereignty, how far would the national territoriality, the legitimacy ownership right as opposed to international breakout. The text shows that in the midst of these discussions, the Empire took advantage of that time to occupy and settle occupations in the areas of the border. Bolivia, for its part, in a weaker position on the frontier zone, was receptive to fugitives from Brazil, which could bring bargaining possibilities in an international agreement on limits, which would be realized eventually.

Keywords: Bolivia. Brazil. Black slavery. Modern States. Borders. 
A fuga da escravidão imperial: Benedita Luiza os jogos de fronteira entre...

\section{Notas}

${ }^{1}$ Para François-Xavier Guerra (2009. p. 248-280, p. 390-417), a reunião das Cortes em Espanha, em 1812, em pleno desafio à ocupação francesa que vinha desde 1808, foi um momento marcante para a "modernidade política", que estava em seus inícios, ao impor uma constituição ao rei ainda cativo pelos franceses. Era essa "modernidade" que colocava em novas bases a ideia de soberania. O rei deveria ser "sujeitado" à carta elaborada pelas "cortes". Na América hispânica, colaborou bastante para isso a "mutação ideológica" (1808-1810), que com a criação de várias juntas governativas em cidades diferentes, acabou-se vislumbrada uma série de novas possibilidades políticas, como a república ou uma monarquia constitucional, ou seja, várias possibilidades alternativas ou que colocassem em xeque a antiga soberania real. Já José Carlos Chiaramonte, por seu turno, centra seu escopo nas antigas doutrinas do Direito Natural e das Gentes como chave para se entender as forças centrífugas de cidades e províncias na formação dos Estados nacionais na América; não menos importante é a consideração da palavra "nação" e "pátria", sendo que especialmente a primeira, no início do século XIX, acabaria por receber um conteúdo essencialmente político, logo procurando delimitar a soberania a determinado território, o que subsidiou conflitos nas décadas iniciais das formações nacionais, por exemplo, entre "centralistas" e "federalistas".

${ }^{2}$ Archivo y Biblioteca Nacionales de Bolivia (ABNB). Fondo Relaciones Exteriores - Juzgado Territorial de Salinas, en San Matías, Juan Ignacio García para Administrador del Cantón de Santo Corazón, 29 de diciembre de 1850.

${ }^{3}$ La Paz tornou-se capital somente em 1899, sendo sede do Poder Executivo. Sucre permaneceu como sede do Poder Judiciário.

${ }^{4}$ Segundo a autora, era com base nessas ideias que se procurou a homogeneização da população em dado território. Procurava-se "apagar" as heterogeneidades étnicas e culturais, para formar um "povo" único de dado país na América hispânica. Não precisamos dizer que tal intento, norteador de muitas políticas no XIX e inícios do XX, não vingou a contento, apesar de muitos "apagamentos" de etnias e culturas. Ver (QUIJADA, 2001, p. 32-56).

${ }^{5}$ Ver García Jordán (2001).

${ }^{6}$ Outra designação das regiões não localizadas na parte andina, indo da parte amazônica aos chacos. Ver Peña Hasbún (2011).

${ }^{7}$ Ver Doratioto (2002), Blanchard (2008) e Grinberg (2013).

${ }^{8}$ Termo que ganhava novo sentido, que, em suma, tornava a "paisagem" o local de uma nova configuração política para a "pátria".

${ }^{9}$ Entre outros, ver Blanchard (2008, p. 76) 
${ }^{10} \mathrm{O}$ imperador do Brasil, D. Pedro, resolveu essa disputa em 1824, com muita cautela, procurando diminuir os ânimos, mas escolhendo Cuiabá como capital, a região que passara a ser mais rica diante da decadência mineral naquele momento (SIQUEIRA, 2002, p. 86-87). Se era necessário procurar manter a ordem em todo o Império que se construía, mais ainda necessário era buscar uma harmonia com os grupos locais da região fronteiriça do Brasil, pois uma rebelião em tal lugar seria bastante difícil de debelar, tanto pela distância (cerca de três meses de viagem por terra) como pela própria posição estratégica frente às repúblicas que se formavam na enorme vizinhança. Ver Sena (2009).

${ }^{11}$ Ver Camargo (2006).

${ }^{12}$ Para um quadro mais detalhado sobre vários países da América latina e o período das leis de abolição do tráfico, lei do ventre livre e "abolição final" da escravidão, ver Andrews (2007).

${ }^{13}$ Além de poucos, a maioria se concentra no período colonial, logo, quando não existia "Bolívia". Conforme levantamento de Revilla Orías (2013, p. 222-224), com o qual concordamos, somente há cotejamentos sobre escravos na Bolívia em trabalhos que tratam de outros assuntos, ainda assim, tendo praticamente por base unicamente o texto pioneiro (e quase único) de Crespo sobre a república (é abordado também no livro o período colonial).

${ }^{14}$ A autora mostra o quanto recente é o movimento "afro-boliviano", em contrapartida a outros movimentos afros na América, ao mesmo tempo que apresenta dados sobre os negros na Bolívia. O senso da virada do século XIX para o XX registrou 3.945 negros em uma população de 1,8 milhões de habitantes. A maioria residente no vale dos Yungas, em La Paz, um território que deixou os negros relativamente ilhados até há poucas décadas. Antes do censo de 2012, havia números discrepantes em relação ao total de afro-bolivianos, indo de oito a 35 mil, dependendo de quais órgãos os estipulavam. De toda forma, atualmente podemos consultar os dados do censo de 2012, que contou com o critério da autodeclaração "afroboliviano", no qual foram registradas 16.329 , em uma população de mais de dez milhões (INE-BOLIVIA, 2013). Fugiria demais dos objetivos deste trabalho debatermos os termos de "auto-declaração", mas pode-se imaginar o quão foram diferentes as sociedades com fortes zonas de plantation e um país com relativa pouca quantidade de negros. Ademais, como mostra Lisocka-Jaegermann (2011, p. 327), a grande "dicotomia” que é vivida hoje em dia na Bolívia é entre Altiplano e Tierras Bajas, o que equivale a Cholo e Camba. Assim, na economia mais dinâmica da Bolívia, Santa Cruz de la Sierra, não faltam demonstrações de preferências ao trabalhador negro do que ao Aymara (colocado genericamente como cholo). A esse último cabe o maior preconceito e estigma de personificar o "obstáculo histórico" ao desenvolvimento do país.

Anos 90, Porto Alegre, v. 25, n. 47, p. 191-219, jul. 2018 
A fuga da escravidão imperial: Benedita Luiza os jogos de fronteira entre...

${ }^{15}$ Como veremos adiante, a contínua entrada de brasileiros armados na Bolívia levantaria muitas queixas, pois claramente desconsiderava a soberania boliviana. ${ }^{16}$ Ver Sena (2013, p. 94.)

${ }^{17}$ Aqui, em uma perspectiva apresentada por Elias, na qual o indivíduo e a sociedade são percebidas de maneira relacional, descartando a independência das duas esferas de ação e percepção.

${ }^{18}$ Archivo y Biblioteca Nacionales de Bolivia (ABNB) - Ministerio de Relaciones Exteriores (MRE). Casa de gobierno para Ministerio de Relaciones Exteriores. Santa Cruz, en 21 de septiembre de 1849.

${ }^{19}$ Ibidem.

${ }^{20}$ ABNB MRE - Prefectura del departamento de Santa Cruz al Presidente de la provincia de Mato-Grosso. Santa Cruz, a 5 de febrero de 1851.

${ }^{21}$ Archivo y Biblioteca Nacionales de Bolívia. Ministerio de Relaciones Exteriores. Caja 8. José Ignacio de S. Ignacio de Sanjines, El Oficial Mayor al Exmo. Snor. Ministro de Relaciones Exteriores del Imperio Constitucional del Brasil - Palacio de Gobierno en Chuquisaca a 15 de marzo de 1837.

${ }^{22}$ Nos primeiros vinte anos de república, por treze vezes o presidente foi substituído, por dez pessoas diferentes.

${ }^{23}$ ABNB. Fondo MRE. Juzgado territorial de las Salinas al señor Administrador de Santo Corazón. San Matías, diciembre 29 de 1850.

${ }^{24}$ Leverger teria dado ordem para que as tropas não passassem do Corixo, um destacamento que ficava defronte de outro, também boliviano, San Matías. Pode-se depreender das documentações que eram pontos estratégicos, que daí muitos comerciantes e outras pessoas passavam de um país ao outro. Logo, aí foram montados postos de fiscalização.

${ }^{25}$ ABNB. MRE. Presidencia da Provincia de Matto Grosso para Prefectura de Santa Cruz. Cuiabá, 30 de maio de 1851.

${ }^{26}$ ABNB. MRE. Prefectura de Santa Cruz para Ministro de Relaciones Exteriores. Santa Cruz, 28 de mayo de 1852.

${ }^{27}$ ABNB. MRE. Juzgado territorial de las Salinas para Administrador de Santo Corazón. San Matías, 12 de diciembre de 1850.

${ }^{28}$ Chiquitos era uma governadoria do departamento de Santa Cruz de la Sierra. $\mathrm{O}$ departamento seria a unidade administrativa aproximada às províncias do Brasil imperial.

${ }^{29}$ Por vezes, administradores de instâncias menores do que a da prefeitura escreviam diretamente para o presidente da província de Mato Grosso, pois, diante de situações que reclamavam urgência e lhes causavam muita indignação e/ou angústia, não podiam esperar a resposta de autoridade superior de seu próprio país.

Anos 90, Porto Alegre, v. 25, n. 47, p. 191-219, jul. 2018 
${ }^{30}$ ABNB. MRE. Juzgado territorial de las Salinas al Señor Administrador de Santo Corazón. San Matías, 29 de diciembre de 1850.

${ }^{31}$ Ver ABNB. MRE. Quartel do Ponto da Corixa para Juizado Territorial das Salinas. Corixa, 29 de dezembro de 1850.

32 No entanto, como mostra a autora, a partir da década de 1860 , criou-se uma jurisprudência, amplamente empregada, na qual a "sedução" de cativos não seria mais enquadrada entre os crimes descritos como "furto" e "roubo" (FLORES, 2014 p. 158).

${ }^{33}$ ABNB. MRE. Santa Cruz, casa de gobierno al Ministro de Instrucción Pública y del Culto y de Relaciones Exteriores. Santa Cruz, 11 de septiembre de 1852. ${ }^{34}$ Sem necessariamente ser demérito dessas publicações, pois, pelo contrário, são chaves para quem estuda a Bolívia, as publicações sobre história geral boliviana pouco ou definitivamente nada abordam sobre escravos e negros no século XIX, como Klein (1992), ao tratar da evolução multiétnica e social boliviana, Sandoval Rodríguez (1999), que desenvolve uma história com acentuação estruturalista, e José de Mesa, Teresa Gisbert e Carlos Mesa Gisbert (2003), que se apoiam bastante nos eventos políticos. Mesmo os "gerais" sobre, especificamente, Santa Cruz de la Sierra, como Roca (2001) e ainda Sandoval Rodriguez (2003), se atêm à escravidão. Inclusive, uma monografia específica sobre a indústria açucareira em Santa Cruz, feita por García Enríquez (2013), a qual, em várias partes da América, era ligada à escravidão negra, a mão de obra referida é basicamente a de grupos indígenas e mestiços. Em nenhum caso, por exemplo, trata da "peonaje" ou "engaje" de africanos e seus descentes, ao contrário do que é apontado aos indígenas e mestiços. De toda forma, não acredito que esse "apagamento" foi pura deliberação dos autores. Pode ser, sim, além de uma documentação não tão abundante, a experiência variada sob a perspectiva das "grandes dicotomias bolivianas" expressadas anteriormente por Lisocka-Jaegermann.

${ }^{35}$ ABNB. MRE. Juzgado territorial de las Salinas para Administrador de Santo Corazón. San Matías, 12 de diciembre de 1850.

${ }^{36}$ Nesse sentido, para as transformações da Grã-Bretanha, notadamente quando são abordados os séculos XVIII e XIX, para muito além da Revolução industrial, ver Ferguson (2016). 
A fuga da escravidão imperial: Benedita Luiza os jogos de fronteira entre...

\section{Referências}

ANDREWS, George Reid. América afro-latina, 1800-2000. São Carlos: EdUSCAR, 2007.

BETHELL, Leslie. A Grã-Bretanha e a América Latina - 1830-1930. In: BETHELL, Leslie (Org.). História da América Latina. Vol. IV. São Paulo: Edusp; Brasília: Fundação Alexandre de Gusmão, 2002.

BLANCHARD, Peter. Under the flag of freedom: slave soldiers and the wars of independence in Spanish - South America. Pittsburg: University of Pittsburg Press, 2008.

CAMARGO, José Alfredo Cavalcanti Jordão de. Bolívia - A criação de um novo país: a ascensão do poder político autóctone das civilizações pré-colombianas a Evo Morales. Brasília: FUNAG, 2006.

CRESPO RODAS, Alberto. Esclavos negros en Bolivia. La Paz: Editorial G.U.M., Bolivia, 1977.

DALENCE, José M. Bosquejo estadístico de Bolivia. Sucre: Imprenta Nacional, 1851.

DORATIOTO, Francisco. Maldita Guerra - nova história da Guerra do Paraguai. São Paulo: Companhia das Letras, 2002.

FERGUSON, Nial. Império - como os britânicos fizeram o mundo moderno. São Paulo: Planeta, 2016.

FERREIRA, Gabriela Nunes. Conflitos no Rio da Prata. In: GRINBERG, Keila; SALLES, Ricardo (Org.). O Brasil Imperial (1808-1831). vol. 1. Rio de Janeiro: Civilização Brasileira, 2009.

FLORES, Mariana da Cunha Thompson. Crimes de fronteira: a criminalidade na fronteira meridional do Brasil (1845-1889). Porto Alegre: EdiPUCRS, 2014. FOUCHER, Michel. L'invention des frontières. Paris: F.E.D.N., 1986.

GARCÍA ENRÍQUEZ, Fernando Aníbal. Historia de la indústria zucarera cruceña. Santa Cruz de la Sierra: Editorial El País, 2013.

GARCÍA JORDÁN, Pilar. Cruz y arado, fusiles y discursos. La construcción de los Orientes en el Perú y Bolivia 1820-1940. Lima: Editora IFEA/IEP, 2001. GOMES SANTOS, Luís Cláudio Villafañe. O Brasil entre a América e a Europa: o império e o interamericanismo. São Paulo: Unesp, 2003.

. O Império e as Repúblicas do Pacífico - as relações do Brasil com Chile, Bolívia, Peru, Equador e Colômbia (1822-1889). Curitiba: Editora UFPR, 2002.

Anos 90, Porto Alegre, v. 25, n. 47, p. 191-219, jul. 2018 
GRINBERG, Keila. Escravidão, alforria e direito no Brasil oitocentista: reflexões sobre a lei de 1831 e o "princípio da liberdade" na fronteira sul do Império brasileiro. In: CARVALHO, José Murilo de. Nação e cidadania no Império: novos horizontes. Rio de Janeiro: Civilização Brasileira, 2007. p. 267-286.

. Fronteiras, escravidão e liberdade. In: GRINBERG, Keila (Org.). As fronteiras da escravidão e da liberdade no sul da América. Rio de Janeiro: 7 Letras: Faperj, 2013. p. 7-24.

GUERRA, François-Xavier. Modernidad e independencias. Madrid: Ed. Encuentro, 2009.

HORNE, Gerald. O sul mais distante. Os Estados Unidos, o Brasil e o tráfico de escravos africanos. São Paulo: Companhia das Letras, 2010.

INC-BOLIVIA. Principales resultados del Censo Nacional de Población y vivenda 2012. La Paz: Instituto Nacional de Estadística: Estado Plurinacional de Bolivia, 2013.

KLEIN, Hebert S. Bolivia - The evolution of a Multi-Ethnic Society. New York: Oxford Press, 1992. . Historia de Bolivia. La Paz: Librería Editorial G.U.M., 2008.

LIMA, André Nicácio. Mato Grosso e a geopolítica da independência (1821-1823). Territórios \& Fronteiras, Cuiabá, v. 5, n. 2, p. 3-31, jul./dez., 2012.

LISOCKA-JAEGERMANN, Bogumila. Los afrodescendientes en los países andinos. El caso de Bolivia. Revista del CESLA [en linea] 2010, 1 (Sin mes). Disponible en: <http://www.redalyc.org/articulo.oa?id=243316419024〉. Fecha de consulta: 7 en. 2018. ISSN 1641-4713

LOMBARDI, John V. A independencia y esclavitud en el período de transición de 1750-1850. In: CARRERAS DAMAS, Gérman; LOMBARDI, John V. (Dir). Historia General de América Latina. Paris: Unesco; Madrid: Trotta, 2003. vol. IV.

LORDELO, Monique Cristina de Souza. "Escravos Negros na Fronteira entre Brasil e Bolívia”. In: SHEIDT, Eduardo; MOURA, Ana Maria S.; RODRIGUES, Fernando da S.; MONTEIRO, Cláudio A. (Orgs.). História social das fronteiras. Jundiaí: Paco Editorial, 2012.

MARQUESE, Rafael de Bivar; PARROM, Tâmis Peixoto. Internacional escravista: a política da Segunda Escravidão. Topoi. Rio de Janeiro, v. 12, n. 23, p. 97-117, 2011. 
A fuga da escravidão imperial: Benedita Luiza os jogos de fronteira entre...

MARQUESE, Rafael de Bivar; TOMICH, D. O Vale do Paraíba escravista e a formação do mercado mundial do café no século XIX. In: GRINBERG, Keila; SALLES, Ricardo (Org.). O Brasil Imperial (1831-1870). Rio de Janeiro: Civilização Brasileira, 2009. v. 2.

MESA, José de; GISBERT, Teresa; MESA GUISBERT, Carlos. Historia de Bolivia. 7. ed. La Paz: Editorial Gisbert y Cia, 2008.

PAMPLONA, Marco A.; DOYLE, Don H. Nação e nacionalismo no novo mundo: a formação de Estados-nação no século XIX. Rio de Janeiro: Record, 2009.

PEÑA HASBÚN, Paula. La permanente construcción de lo cruceño: un estudio sobre la identidad de Santa Cruz de la Sierra. Santa Cruz: Universidad Autónoma Gabriel René Moreno, 2011.

QUIJADA, Mónica. Homogeneidad y nación - con un estudio de caso: Argentina, siglos XIX y XX. Madrid: CSI, 2000.

REVILLA ORÍAS, Paola. “!Morrir antes de esclavos vivir!” República libertaria y esclavitud negra en Bolivia decimonónica. In: ROBINS, Nicholas A.; RARAHONA MICHEL, Rosario. Mitos expuestos: leyendas falsas de Bolivia. Cochabamba: Editorial Kipus, 2014.

ROCA, José Luis. Economía y Sociedad em el Oriente Boliviano (siglos XVI-XX). Santa Cruz de la Sierra: Editorial Oriente S.A., 2001.

RODRIGUES, Bruno Pinheiro. "Homens de ferro, mulheres de pedra": resistências e readaptações identitárias de africanos escravizados. Do hinterland de Benguela aos vales dos rios Guaporé-Paraguai e América espanhola - fugas, quilombos e conspirações urbanas (1720-1809). Tese (Doutorado) - Instituto de Ciências Humanas e Sociais da Universidade Federal do Mato Grosso, Cuiabá, 2015.

SANDOVAL RODRIGUEZ, Isaac. História de Bolivia - Desarrollo HistóricoSocial. Santa Cruz: Sirena Color, 1999.

Color, 2003.

. História de Bolivia - Desarrollo Histórico-Social. Santa Cruz: Sirena

SANTOS, Corsino Medeiros. O tráfico de escravos do Brasil para o rio da Prata. Brasília: Ed. do Senado, 2010.

SECKINGER, Ron L. La cuestión de chiquitos: una breve crisis en las relaciones boliviano-brasileñas. Revista de la Universidad Gabriel René Moreno. Santa Cruz de la Sierra, n. 39-40, 1985.

SECRETO, Maria Verônica. Asilo: direito de gentes. Escravos refugiados no Império Espanhol. Revista de História, São Paulo, n. 172, p. 197-219, jan./jun., 2015. 
SENA, Ernesto Cerveira de. Entre anarquizadores e pessoas de costumes. Cuiabá: EdUFMT, 2009.

. Fugas e reescravizações em região fronteiriça - Bolívia e Brasil nas primeiras décadas dos Estados nacionais. Estudos Ibero-Americanos, Porto Alegre, v. 39, n. 1, p. 82-98, jan./jun. 2013.

SIQUEIRA, Elizabeth Madureira. História de Mato Grosso. Cuiabá: Entrelinhas, 2002.

TOMICH, Dale W. Pelo prisma da escravidão: trabalho, capital e economia mundial. São Paulo: Edusp, 2011.

VOLPATO, Luiza Rios. Cativos do sertão: vida cotidiana e escravidão em Cuiabá em 1850-1888. São Paulo: Marco Zero; Cuiabá: EdUFMT, 1993.

. Quilombos em Mato Grosso - resistência negra em área de fronteira. In: REIS, João José; GOMES, Flávio dos Santos. Liberdade por um fio: história dos quilombos no Brasil. São Paulo: Companhia das Letras, 1996.

Recebido em: 29/01/2017

Aprovado em: 30/10/2017 
